\title{
BMJ Open Clinical characteristics and outcomes of hyponatraemia associated with oral water intake in adults: a systematic review
}

Gopala K Rangan, ${ }^{1,2}$ Nilofar Dorani, ${ }^{1,3}$ Miranda M Zhang, ${ }^{1,3}$ Lara Abu-Zarour, ${ }^{1,3}$ Ho Ching Lau, ${ }^{1,3}$ Alexandra Munt (D) ,,2 Ashley N Chandra,, Sayanthooran Saravanabavan, ${ }^{1}$ Anna Rangan, ${ }^{4}$ Jennifer Q J Zhang, ${ }^{1,2}$ Martin Howell (D) , ${ }^{5}$ Annette TY Wong ${ }^{1,2}$

To cite: Rangan GK, Dorani N, Zhang MM, et al. Clinical characteristics and outcomes of hyponatraemia associated with oral water intake in adults: a systematic review. BMJ Open 2021;11:e046539. doi:10.1136/ bmjopen-2020-046539

- Prepublication history and additional supplemental material for this paper are available online. To view these files, please visit the journal online (http://dx.doi.org/10.1136/ bmjopen-2020-046539).

ND and MMZ contributed equally.

Received 19 November 2020 Accepted 10 November 2021

Check for updates

(C) Author(s) (or their employer(s)) 2021. Re-use permitted under CC BY-NC. No commercial re-use. See rights and permissions. Published by BMJ.

For numbered affiliations see end of article.

Correspondence to

Dr Gopala K Rangan;

g.rangan@sydney.edu.au

\section{ABSTRACT}

Introduction Excessive water intake is rarely associated with life-threatening hyponatraemia. The aim of this study was to determine the clinical characteristics and outcomes of hyponatraemia associated with excess water intake. Methods This review was conducted using Preferred Reporting Items for Systematic Reviews and MetaAnalyses (PRISMA) guidelines. All studies (case reports, observational or interventional studies) reporting excess water intake and hyponatraemia in adults (1946-2019) were included.

Results A total of 2970 articles were identified and 177 were included (88.7\% case reports), consisting of 590 patients. The mean age was $46 \pm 16$ years $(95 \% \mathrm{Cl} 44$ to 48 years), $47 \%$ female, $52 \%$ had a chronic psychiatric disorder and $31 \%$ had no underlying condition. The median volume of water consumed and serum sodium at presentation was $8 \mathrm{~L} /$ day $(95 \% \mathrm{Cl} 8.9$ to $12.2 \mathrm{~L} /$ day) and $118 \mathrm{mmol} / \mathrm{L}$ (95\% Cl 116 to $118 \mathrm{mmol} / \mathrm{L})$, respectively. The motivator for increased water consumption was psychogenic polydipsia (55\%); iatrogenic (13\%); exercise (12\%); habitual/dipsogenic polydipsia (7\%) and other reasons (13\%). The clinical features on presentation were severe in 53\% (seizures, coma); moderate in 35\% (confusion, vomiting, agitation) and mild in 5\% (dizziness, lethargy, cognitive deficit) and not reported in $5 \%$ of studies. Treatment was supportive in $41 \%$ of studies (fluid restriction, treatment of the underlying cause, emergency care), and isotonic and hypertonic saline was used in $18 \%$ and $28 \%$ of cases, respectively. Treatment-related complications included osmotic demyelination (3\%) and rhabdomyolysis (7\%), and death occurred in $13 \%$ of cases.

Conclusion Water intoxication is associated with significant morbidity and mortality and requires daily intake to substantially exceed population-based recommendations. The limitations of this analysis are the low quality and high risk of bias of the included studies.

PROSPERO registration number A pre-existing protocol in the international prospective register of systematic reviews was updated to incorporate any new amendments and reregistered at http://www.crd.york.ac.uk/PROSPER0 (registration no. CRD42019129809).
Strengths and limitations of this study

- Provides evidence on the potential dangers of overhydration.

- Reports the median volume of water consumed associated with water intoxication.

- Emphasises the importance of practitioners providing specific education when advising patients to increase water intake .

- Majority of studies (88.7\%) were low quality, as they were derived from case reports/case series, and therefore, a high risk of bias.

- Water volume consumed and exposure time were self-reported or observed, reducing the precision of the estimate.

\section{INTRODUCTION}

Self-induced water intoxication is a rare but serious complication of excessive fluid intake and the first case report was described in $1938 .^{1}{ }^{2}$ It occurs when the oral intake of solute-free fluid per unit time exceeds the capacity of the kidney to excrete water (0.8-1.0 L per hour) leading to hypo-osmolar hyponatraemia. ${ }^{13-5}$ The exact incidence of water intoxication in the general population is not known but suspected to be very rare due to the excretory capacity of the kidney. ${ }^{6}$ In the defence forces, water intoxication occurred in 6.9 cases per 100000 personyears $(2001-2016)^{7}$ but the prevalence may be as high as $5 \%(3.3-5.8 \%)$ in hospitalised psychiatric patients. ${ }^{8} 9$ In the military, the incidence of water intoxication declined by $23.3 \%$ over the last decade due to education programmes. ${ }^{7}$ The clinical manifestations of water intoxication depend on severity of hyponatraemia, and range from headaches, nausea, confusion, seizures and rarely death, due to cerebral oedema. ${ }^{3}$

In the published literature, multiple causes for water intoxication have been reported 
and include situational circumstances (soldiers undertaking strenuous work in hot weather; athletes overhydrating during endurance exercise or other competitive events; iatrogenic polydipsia due to misinterpretation of medical advice; habitual/dipsogenic polydipsia, in which water drinking is perceived to have health benefits). ${ }^{10-13}$ In addition, chronic comorbidities (particularly schizophrenia spectrum disorders, beer potomania, low dietary solute intake), concomitant medications (neuroleptic drugs, thiazide diuretics) ${ }^{14}$ recreational drug use (such as 3,4-methylenedioxymethamphetamine, MDMA) $)^{5}$ 15-19 and smoking ${ }^{21}{ }^{21}$ reduce the water volume required to cause intoxication by up to $33 \%$ due to concurrent antidiuretic hormone release which impairs the renal capacity to excrete solute-free urine. ${ }^{51719}$ Other comorbid conditions and personal dietary habits, such as beer potomania and low dietary solute, also lower the threshold for water intoxication due to a decrease in obligatory urine volume required for urinary solute excretion. ${ }^{5} 171922$

There has been long-standing interest on if there is an optimal amount of daily water intake required to maintain normal health span and prevent chronic disease. ${ }^{1822}{ }^{23}$ Interestingly, a recent observational cohort study suggested that water intake may have a U-shaped relationship in the prevention of kidney disease progression. ${ }^{24}$ Hence, clinical trials are in progress to prospectively evaluate the efficacy and safety of prescribed water intake for the secondary prevention of chronic diseases. ${ }^{25-27}$ Whether recommending water intake in healthcare ${ }^{27}$ or prescribing water intake in a clinical research trial it is important to understand the circumstances that could result in water intoxication. ${ }^{517}$ Recently, a comprehensive narrative review on the pathogenesis of overhydration was published, ${ }^{28}$ and therefore, the primary aim of this study was to perform a systematic review to determine the characteristics (demographics, comorbidities, volume of water consumed) associated with water intoxication. The secondary aims were to investigate the clinical features, treatment and outcomes.

\section{METHODS}

\section{Protocol and registration}

This systematic review was conducted and reported in accordance with the Preferred Reporting Items for Systematic Reviews and Meta-Analyses (PRISMA) guidelines. ${ }^{29}$

\section{Eligibility criteria}

Studies were considered eligible if the following criteria were met: studies were case reports, observational cohort studies or randomised controlled trials; participants were humans aged 18 years and above and water intoxication was reported (table 1). ${ }^{30}$ Studies were excluded if: they were review articles or editorial/discussion papers; they reported non-oral routes of water administration (eg, intravenous) or non-water induced hyponatraemia (eg, syndrome of inappropriate antidiuretic hormone); the serum sodium values were absent; or studies involved
Table 1 Population, intervention, comparator and outcome characteristics of the inclusion criteria

\begin{tabular}{|c|c|}
\hline Population & $\begin{array}{l}\text { Adults with or without comorbid conditions } \\
\text { with water intoxication }\end{array}$ \\
\hline Intervention & Oral water intake \\
\hline Comparator & No intervention \\
\hline Outcomes & $\begin{array}{l}\text { Clinical characteristics, volume of water } \\
\text { intake, serum sodium levels, treatment and } \\
\text { outcome }\end{array}$ \\
\hline Setting & All \\
\hline Study Design & $\begin{array}{l}\text { Case reports, observational cohort studies } \\
\text { or randomised controlled trials }\end{array}$ \\
\hline
\end{tabular}

children or animals. Studies that examined other beverage types (eg, soft drinks) were only included if they were reported in conjunction with plain water or incorporated within total fluid intake. All literature was restricted to English.

\section{Information sources and search strategy}

The search strategy was developed by the authors (ND, MMZ, LA-Z and HCL) with input from an expert reference librarian. Relevant medical subject headings and keywords (such as 'water intoxication' and 'hyponatraemia'; the full list of search terms is provided in online supplemental data file 1) were used to search databases (MEDLINE, EMBASE, Cochrane Library, Cochrane Database of Systematic Reviews and Cochrane Clinical Answers). Search strategies were developed for MEDLINE (OvidSP; 1946-2019), and adapted for EMBASE (OvidSP 1947-2019), CINAHL (EBSCO 1982-2019) and Cochrane Library (OvidSP 1991-2019) including CENTRAL, Cochrane Database of Systematic Reviews and Cochrane Clinical Answers. Additional hand-searches of relevant reference lists and supplementary journals were also conducted. All database searches were completed on 13 August 2019.

\section{Study selection}

Search results from the databases were exported into EndNote V.X9 (Clarivate Analytics, USA) and duplicate records discarded. Titles and abstracts of all literature were screened to ensure relevance to the selection criteria, and any irrelevant articles were excluded. Full texts of the remaining articles were sourced and screened against inclusion and exclusion criteria in consultation with other researchers in the team (AW and GKR). Approved articles were subsequently incorporated into the systematic review, and reasons provided for excluded articles. The screening process was completed independently by two reviewers (ND and MMZ) which was further crosschecked by two coauthors (LA-Z and HCL).

\section{Data collection process and data items}

A data extraction form was developed to incorporate the following information: author, year, study design, patient demographics (age, gender, country of origin); 
comorbidity (chronic psychiatric condition (schizophrenia spectrum, bipolar, disorders, anxiety, obsessivecompulsive disorders, eating disorders), chromic medical disease (cardiovascular, kidney, liver, cancer, diabetes) $)^{31}$; reason for water consumption (psychogenic, habitual/ dipsogenic, exercise-associated, iatrogenic, illicit drug use; urinary tract infection, competition-related polydipsia); concomitant medications (classified as either: no medication; medications associated with hyponatraemia; medications not associated with hyponatraemia ${ }^{14}$; volume consumed, sodium values (serum sodium, sodium levels in vitreous humour), symptom onset (acute: $<48$ hours; chronic: $>48$ hours); clinical features by severity (mild: either dizziness, light-headedness, nausea, headache; moderate: vomiting, confusion, agitation, dyspnoea, altered mental status; severe: seizures, coma, decorticate posturing, mydriasis) ${ }^{32}$; treatment types (supportive, isotonic or hypertonic saline), treatment-related complications (none, osmotic demyelination (OMD)) and outcomes (recovery, death). Data extraction and coding was performed by two authors (ND and MMZ), and verified by a third author (GKR).

\section{Quality assessment}

The quality assessment of the selected studies was performed independently by two authors (ND and MMZ) and cross-checked by two coauthors (LA-Z and HCL) using a modified version of the Newcastle-Ottawa Scale (NOS) for cohort studies/case reports. ${ }^{33}{ }^{34}$ The scale assessed the standard four domains of the NOS (selection, ascertainment, causality and reporting) using eight questions to classify the selected literature as either 'low' (score of 0 ) or 'high' quality (score of 8). In the case of any disagreements, third reviewers were consulted (AW and GKR).

\section{Patient and public involvement statement \\ No patient involved.}

\section{Data synthesis and analyses}

Due to the heterogeneity of studies, a meta-analysis was not considered appropriate. The study results were summarised to outline the main outcomes of interest: age, gender, comorbidities (psychiatric, medical, none), concomitant medications (categorised by whether patients received one or more drugs that cause hyponatraemia); reason/s for water intake; volume of water consumed; clinical features (mild, moderate, severe) and onset; treatment types and complications, and outcomes. Data for water volume per unit time were divided into two groups consisting of an amount consumed per day (if the value reported for time was 1 day) or standardised to a 4-hour period (if the value for time was less than 1 day). Data from individual case reports were collected and mean values from aggregated data in case series or cohort studies. Descriptive statistics (mean, median, IQR and $95 \%$ CIs) were performed using JMP Pro statistics software (V.14, SAS Institute).

\section{RESULTS}

\section{Study selection}

The initial search revealed 2970 articles and after identifying duplicate records and screening title and abstracts, 1801 articles were excluded, leaving 310 full-text articles (figure 1). Of the 310 full-text articles screened for eligibility, 177 were included in the final synthesis. ${ }^{6-11} 131932$ 35-204 The summary and full descriptions of all included studies and reasons for exclusion are provided in the online supplemental data files 2-4.

\section{Study characteristics}

The 177 articles selected for inclusion contained data from a total of 590 patients, consisting of 223 individual case reports $(n=119)$ and case series $(n=24)$. The majority of the articles were case reports/case series $(88.7 \%$; $\mathrm{n}=157)^{6} \quad 10 \quad 11 \quad 13 \quad 32 \quad 35-41 \quad 43-52 \quad 55-70 \quad 73 \quad 74 \quad 76-78 \quad 80-84 \quad 86-88 \quad 91-103$ 105-119 121-129 131-135 137-161 163-165 167-193 195-204 followed by retrospective cohort studies ( $\mathrm{n}=10),{ }^{9}{ }^{53} 758590104120136194$ prospective cohort studies $(\mathrm{n}=5),{ }^{42} 547189166$ case-control studies $(\mathrm{n}=3),{ }^{19} 72162$ a cross-sectional study $(\mathrm{n}=1)^{79}$ and a prospective uncontrolled study $(\mathrm{n}=1)^{130}$ (table 2$)$.

\section{Quality of studies}

The risk of bias assessment score based on the number of studies is summarised in table 3 and reported in more detail in online supplemental data file 5 . The majority of studies $(n=118 ; 66.7 \%$ of total) ranked as having a medium to high risk of bias.

\section{Patient characteristics \\ Age, gender and country}

Age was not reported for 25 patients $(\mathrm{n}=8$ in individual case reports; one case series consisting of $n=17$ patients). In the remaining patients $(n=565)$, the mean age was $46 \pm 16$ years (mean $\pm \mathrm{SD})(95 \%$ CI 44 to 48 years) (table 4 ). In patients with a specified gender $(n=526), 47 \%$ were female and $53 \%$ were male. The majority of studies were from the USA $(n=66 ; 37.3 \%)$, Japan $(n=18 ; 10.2 \%)$, the UK $(n=17 ; 9.6 \%)$, Israel $(n=9 ; 5.1 \%)$ and Australia $(n=8$; $4.5 \%)$.

\section{Comorbidities}

The majority of patients suffered from a chronic psychiatric condition $(52 \%)$, consisting predominantly of schizophrenia spectrum disorders and to a lesser extent others (bipolar, cognitive impairment, anxiety, personality and depressive disorders; dementia and anorexia nervosa) (table 4). Fifteen per cent patients suffered from an underlying chronic medical condition that led to the consumption of excess water (such as intractable hiccups, a urinary tract infection, dry mouth, low dietary solute) and/or exacerbated the risk for water intoxication. Approximately one-third of studies (31\%) reported that patients had no underlying health condition (table 4). Data on smoking were missing in the majority (91.4\%) of studies. 


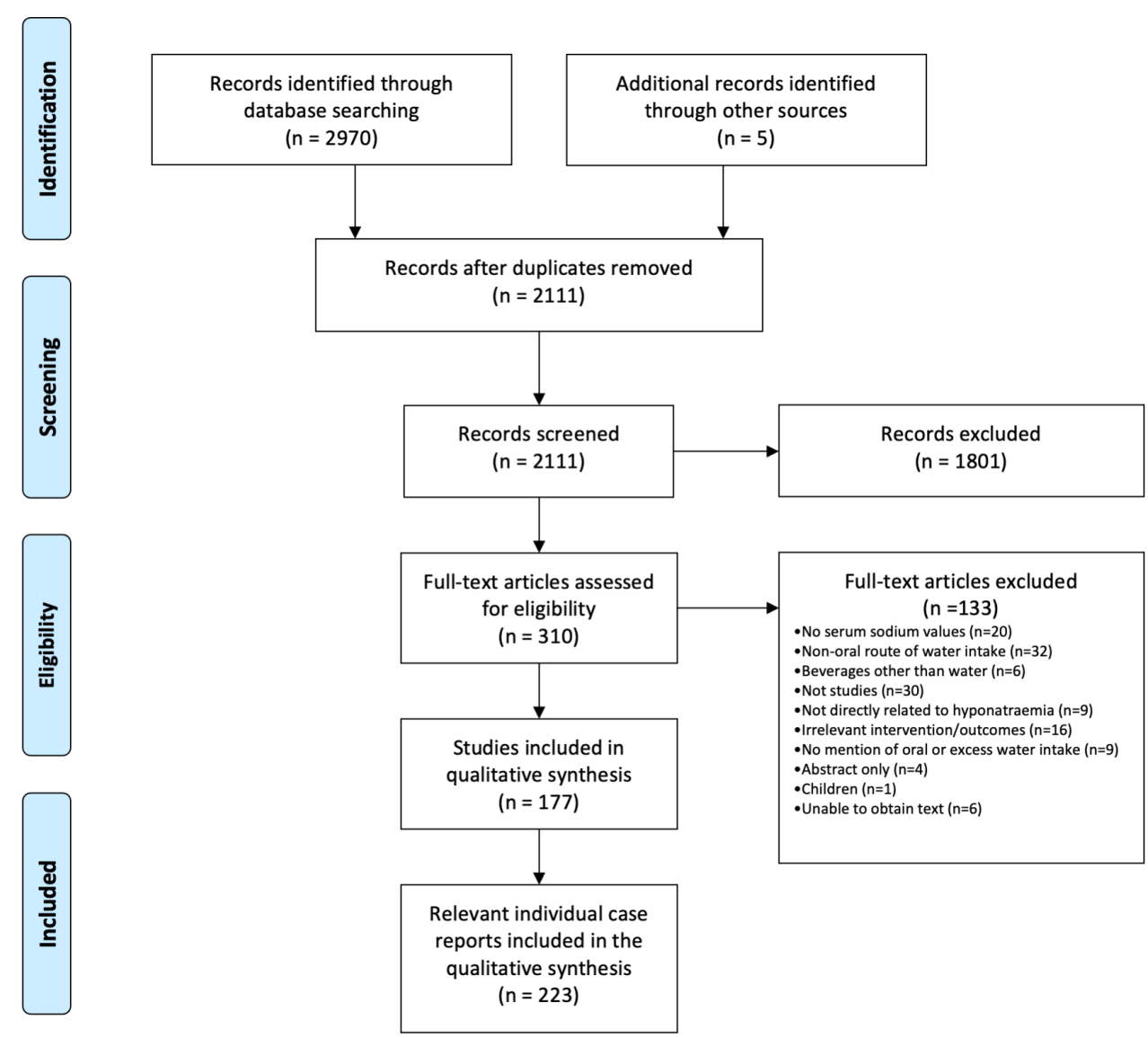

Figure 1 PRISMA flow diagram outlining the literature selection process.

\section{Concomitant medications}

Data for concomitant medications were not available in $31 \%$ of case reports/case series (table 4 ). In a quarter $(23 \%)$ of case reports/case series patients were not taking any medications; another $41 \%$ were associated with exacerbating hyponatraemia ${ }^{14}$ whereas the remainder $(5 \%)$ were not taking medications that could contribute to lowering of the serum sodium (table 4 ). Of the former, the majority were antipsychotic drugs $(68 \%)$, diuretics $(13 \%)$, antidepressants $(5 \%)$ and miscellaneous drugs (14\%) (such as cyclophosphamide, carbamazepine, complementary medicines) (table 4).
Volume of water consumed and serum sodium levels

Reasons for increased water consumption

In the majority, the cause was due to psychogenic polydipsia $(55 \%)$ (mainly associated with the presence of schizophrenia spectrum disorder) (figure 2); $13 \%$ of causes were due to iatrogenic polydipsia where water intake was recommended on medical advice, such as preparation for an ultrasound; $12 \%$ of cases were associated with exercise; $7 \%$ of cases were due to habitual/ dipsogenic polydipsia; $2 \%$ there were multiple reasons; and the remainder of cases $(11 \%)$ included miscellaneous conditions [self-remedy for an infection (urinary tract infection, gastroenteritis, respiratory tract infection) ]; avoidance of substance abuse through urine drug testing; intractable hiccups; involvement in a research

Table 2 Characteristics of studies that met the inclusion criteria

\begin{tabular}{lll}
\hline Study design & No of articles $\mathbf{n}(\%)$ & No of patients N (\%) \\
\hline Case reports & $157(88.7)$ & $219(37.1)$ \\
\hline Retrospective cohort studies & $10(5.6)$ & $254(43.1)$ \\
Prospective cohort studies & $5(2.8)$ & $44(7.5)$ \\
Case-control studies & $3(1.7)$ & $36(6.1)$ \\
Cross-sectional study & $1(0.6)$ & $27(4.6)$ \\
Prospective uncontrolled study & $1(0.6)$ & $10(1.7)$ \\
Total & $177(100)$ & $590(100)$ \\
\hline
\end{tabular}




\begin{tabular}{lll}
\hline Table 3 & Risk of bias assessment & \\
\hline Score & No of publications & Risk of bias \\
\hline 1 & 0 & High \\
2 & 5 & High \\
3 & 20 & Medium \\
4 & 53 & Medium \\
5 & 40 & Medium \\
6 & 15 & Low \\
7 & 18 & Low \\
8 & 26 & Low \\
\hline
\end{tabular}

study or participation in a competition; use of illicit drugs such as MDMA; paruresis) (table 4).

Volume of water consumed

There was wide heterogeneity in the method of reporting the volume of water that was consumed. Of the 223 case reports/case series, quantitative data were provided in $56 \%(\mathrm{n}=125 / 223)$, qualitative information alone in $40 \%(\mathrm{n}=90 / 223)$ and no data was reported in $4 \%(8 / 223)$ (table 4$)$. In addition, the quantitative data that was provided in the case reports/case series were either self-reported or estimated by observers of the patient (family, friends, medical staff). In cases that provided a quantitative

Table 4 Summary of demographics, serum sodium and water intake volumes in the case reports/case series

\begin{tabular}{|c|c|c|c|c|}
\hline & All & $\begin{array}{l}\text { Mild hyponatraemia } \\
(130-134 \mathrm{mmol} / \mathrm{L})\end{array}$ & $\begin{array}{l}\text { Moderate } \\
\text { hyponatraemia } \\
(125-129 \mathrm{mmol} / \mathrm{L})\end{array}$ & $\begin{array}{l}\text { Severe } \\
\text { hyponatraemia } \\
\text { (<125 mmol/L) }\end{array}$ \\
\hline Mean age (years) $(95 \% \mathrm{Cl})^{*}$ & $46 \pm 16$ (43.6 to 48.0$)$ & $38 \pm 10$ (30.3 to 45.0$)$ & 41 (35 to 47 ) & 47 (45 to 49$)$ \\
\hline Male:female $(\%) \dagger$ & $53: 47$ & 67: 17 & 62: 38 & $52: 48$ \\
\hline \multicolumn{5}{|l|}{ Comorbidities (\%) } \\
\hline None & $31 \%(69 / 223)$ & $50 \%(5 / 10)$ & $44 \%(12 / 27)$ & $28 \%(52 / 186)$ \\
\hline Medical condition & $15 \%(33 / 223)$ & $0 \%(0 / 10)$ & $11 \%(3 / 27)$ & $16 \%(30 / 186)$ \\
\hline Psychiatric disorder & $52 \%(117 / 223)$ & $50 \%(5 / 10)$ & $41 \%(11 / 27)$ & $54 \%(101 / 186)$ \\
\hline Both (medical +psychiatric) & $2 \%(4 / 223)$ & $0 \%(0 / 10)$ & $4 \%(1 / 27)$ & $2 \%(3 / 186)$ \\
\hline \multicolumn{5}{|l|}{ Concomitant medications (\%) } \\
\hline Not reported & $31 \%(70 / 223)$ & $30 \%(3 / 10)$ & $44 \%(12 / 27)$ & $30 \%(55 / 186)$ \\
\hline No medications & $23 \%(51 / 223)$ & $50 \%(5 / 10)$ & $26 \%(7 / 27)$ & $21 \%(39 / 186)$ \\
\hline Associated with hyponatraemia & $41 \%(92 / 223)$ & $20 \%(2 / 10)$ & $30 \%(8 / 27)$ & $44 \%(82 / 186)$ \\
\hline Not associated with hyponatraemia & $5 \%(10 / 223)$ & $0 \%(0 / 10)$ & $0 \%(0 / 27)$ & $5 \%(10 / 186)$ \\
\hline \multicolumn{5}{|l|}{ Reason for water intake } \\
\hline Exercise & $12 \%(27 / 223)$ & $50 \%(5 / 10)$ & $29.6 \%(8 / 27)$ & $8 \%(14 / 186)$ \\
\hline latrogenic & $13 \%(29 / 223)$ & $0 \%(0 / 10)$ & $18.5 \%(5 / 27)$ & $13 \%(24 / 186)$ \\
\hline Habitual/dipsogenic & $7 \%(15 / 223)$ & $0 \%(0 / 10)$ & $11.1 \%(3 / 27)$ & $6 \%(12 / 186)$ \\
\hline Psychogenic & $55 \%(123 / 223)$ & $40 \%(4 / 10)$ & $33.3 \%(9 / 27)$ & $59 \%(110 / 186)$ \\
\hline Multiple reasons & $2 \%(5 / 223)$ & $0 \%(0 / 10)$ & $3.7 \%(1 / 27)$ & $2 \%(4 / 186)$ \\
\hline Other & $11 \%(24 / 223)$ & $10 \%(1 / 10)$ & $3.7 \%(1 / 27)$ & $12 \%(22 / 186)$ \\
\hline $\begin{array}{l}\text { Mean serum sodium }(\mathrm{mmol} / \mathrm{L}) \\
(95 \% \mathrm{Cl})\end{array}$ & 118 (116 to 118$)$ & 132 (131 to 133$)$ & 127 (126 to 127$)$ & 114 (113 to 115$)$ \\
\hline $\begin{array}{l}\text { Median water intake per day } \\
\text { (litres) }(95 \% \mathrm{Cl})\end{array}$ & 8.0 (8.9 to 12.2$)$ & $5.0(-2.2$ to 14.5$)$ & 8.0 (5.3 to 9.7$)$ & $9.0(9.2$ to 13.0$)$ \\
\hline $\begin{array}{l}\text { Median water intake over 4-hour } \\
\text { period (litres) }(95 \% \mathrm{Cl}) \S\end{array}$ & 5.3 (5.3 to 8.6$)$ & $3.1(-0.3$ to 8.3$)$ & 6.2 (3.3 to 9.1$)$ & 7.5 (5.4 to 9.6$)$ \\
\hline
\end{tabular}

${ }^{*}$ Age was not reported in $\mathrm{n}=25$ individuals.

†Gender was not reported in $\mathrm{n}=64$ individuals.

$\neq$ Data are from $n=76$ case report/case series.

$\S$ Data are from $n=49$ case report/case series. 


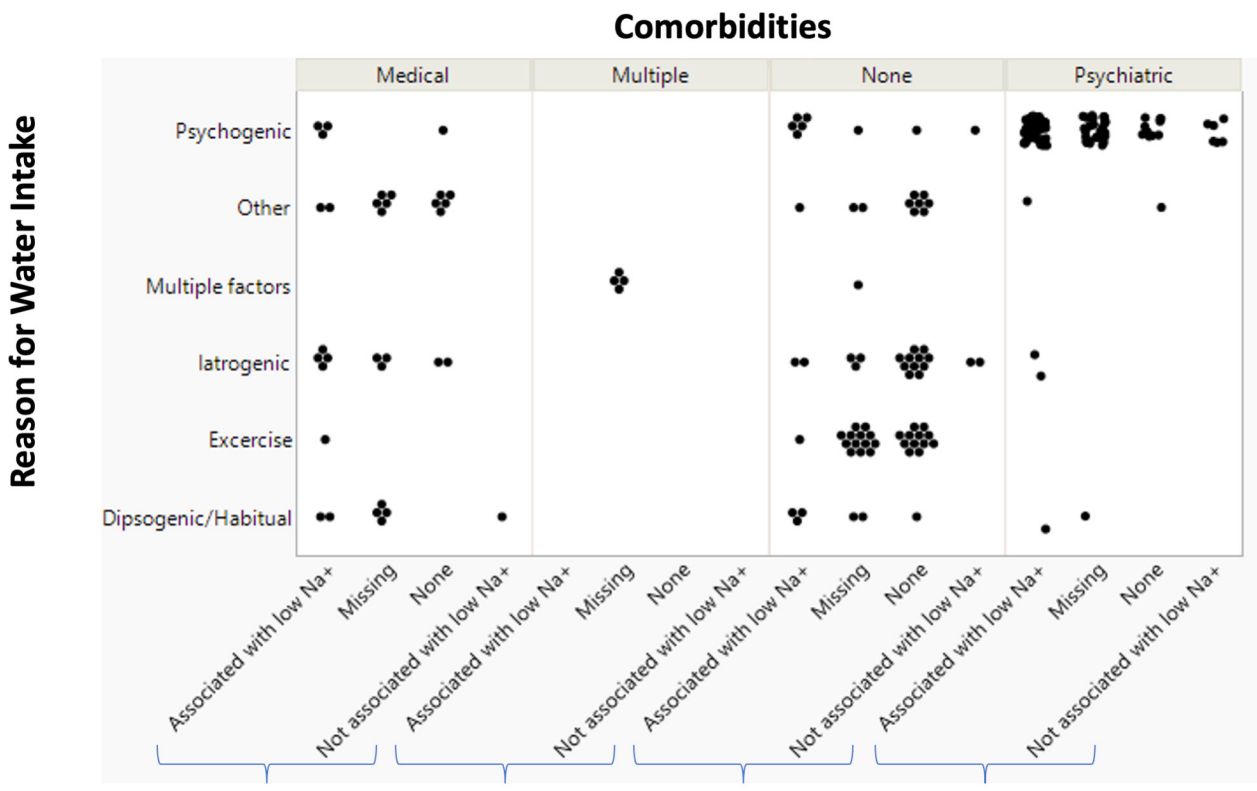

\section{Concomitant Drugs}

Figure 2 Categorisation of cases according to underlying comorbidities, main reason for water intake and use of concomitant drugs associated with hyponatraemia (low $\mathrm{Na}+)$.

value, it was estimated either as an amount consumed in a single day $(\mathrm{n}=76)$ or over hours (median 4 hours, range $0.5-23$ hours; $\mathrm{n}=49$ ). In studies that reported the volume over hours, the median intake of water was $5.3 \mathrm{~L}$ over a 4 -hour period $(95 \%$ CI 5.3 to $8.6 \mathrm{~L})$. In studies that reported the volume in a single day, the median intake of water was $8.0 \mathrm{~L}$ over 24 -hour period (95\% CI 8.9 to 12.2 L) (table 4 ). In 90 cases/case series, only qualitative descriptions were provided to estimate water intake, and in 8 cases/case series no description was included. Of the qualitative studies, common terms to describe water intake included: 'excessive water intake' ( $\mathrm{n}=29)$; 'large amounts' $(\mathrm{n}=18)$; 'compulsive water intake' $(\mathrm{n}=9)$; 'copious quantities' $(n=5)$; 'several litres per day' $(n=4)$; or 'overhydration' $(n=4)$. Some examples of other terms that were used included: 'always at the tap' $(n=1)$; 'plenty of water' $(\mathrm{n}=1)$; 'frequent trips to the water fountain' $(\mathrm{n}=1)$.

\section{Serum sodium levels}

The median serum sodium was $118 \mathrm{mmol} / \mathrm{L}$ (IQR: 111-123; range 83-134 mmol/L). In 6 of 40 fatal cases (29/223 studies), the median vitreous humour was $112 \mathrm{mmol} / \mathrm{L}$ (IQR: 103-116; range 92-117 mmol/L). Age, gender, the median water intake and reasons for water intake were similar in patients with mild, moderate or severe hyponatraemia (table 4). In addition, the scatterbox plot of the data suggested that patients with psychiatric conditions were predisposed to a lower serum sodium level than those with no underlying health problems (figure 3 ).

\section{Clinical features and treatment of water intoxication Clinical features}

Clinical features were not reported in $4.5 \%$ of case reports/case series (table 5). In the remainder, $2.7 \%$ of patients reported no symptoms or signs; in $4.9 \%$ the clinical features were mild in severity (5/10: dizziness; $3 / 10$ : nausea; $1 / 10$ : lethargy; 1/10: cognitive deficit); in $34.5 \%$ the clinical features were moderate in severity $(56 / 76$ : confusion; 13/77 vomiting; 5/77: dyspnoea: 2/77: agitation; 1/77: tremor); and in $53.4 \%$ the symptoms were severe (81/119: seizure; 38/119: coma) (table 5). The onset of clinical features was not reported in $30 \%$ of case reports/case series and in the remainder, the majority were acute (less than 48 hours; 41\%) and chronic (greater than 48 hours; 26\%) and 3\% were asymptomatic (table 5).

\section{Treatment and treatment-related complications}

Treatment was not reported in 13\% of case reports/ case series (table 5). In the remainder, treatment was supportive care $(41 \% ; n=92)$ which included fluid restriction (48/92), antipsychotic drugs (14/92), behavioural therapy: $(9 / 92)$, diuretics $(3 / 92)$, emergency medical care $(3 / 92)$, no treatment $(12 / 92)$ or other (3/92). Twenty-eight and $18 \%$ of case reports/case series reported the use of $3 \%$ hypertonic saline and isotonic saline respectively which was administered in patients with severe hyponatraemia and/or depending on severity of clinical features (table 5 and figure 4 ). Ninety per cent of studies reported no treatment-related complications, but rhabdomyolysis and OMD syndrome occurred in $7 \%(\mathrm{n}=16 / 223)$ and $3 \%(\mathrm{n}=7 / 223)$ of case reports/case 

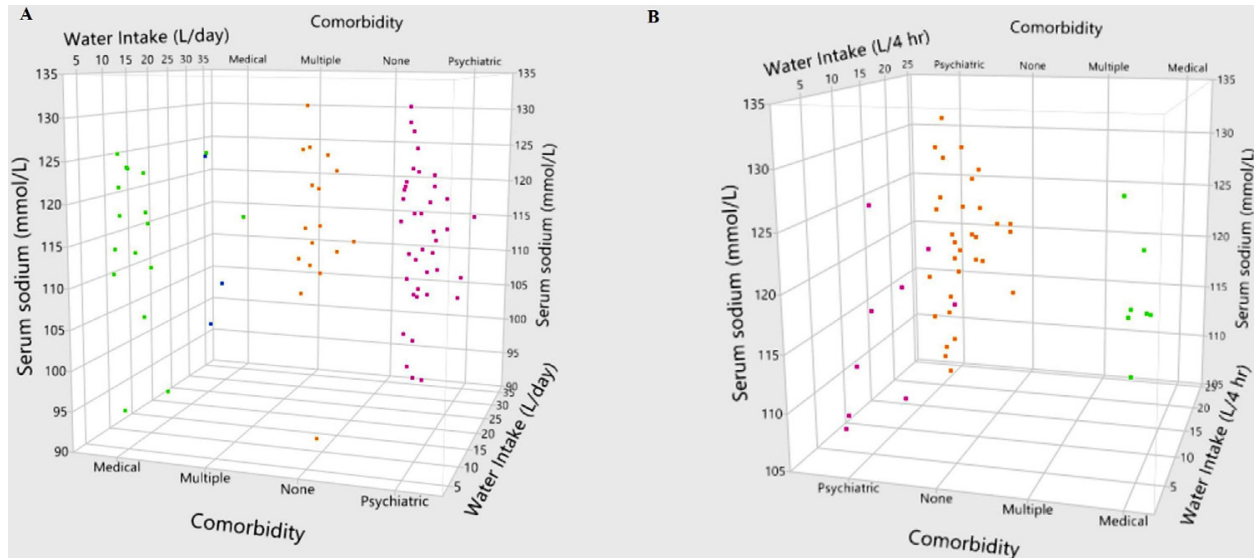

Figure 3 3D scatterplot box to group cases according to water intake (A: litres per day; B: litres over 4 hours), comorbidity and serum sodium. Dots are coloured according to comorbidity group (psychiatric condition, pink; no underlying health condition or none, orange; multiple conditions, blue; medical condition, green). 3D, three dimensions.

series, respectively (table 5). In the cases with rhabdomyolysis, the clinical presentation in $43 \%(7 / 16)$ included seizures.

\section{Outcomes}

The outcome was not reported in $9 \%$ of studies (table 5).

Table 5 Clinical features, patterns of treatment and clinical outcomes of water intoxication

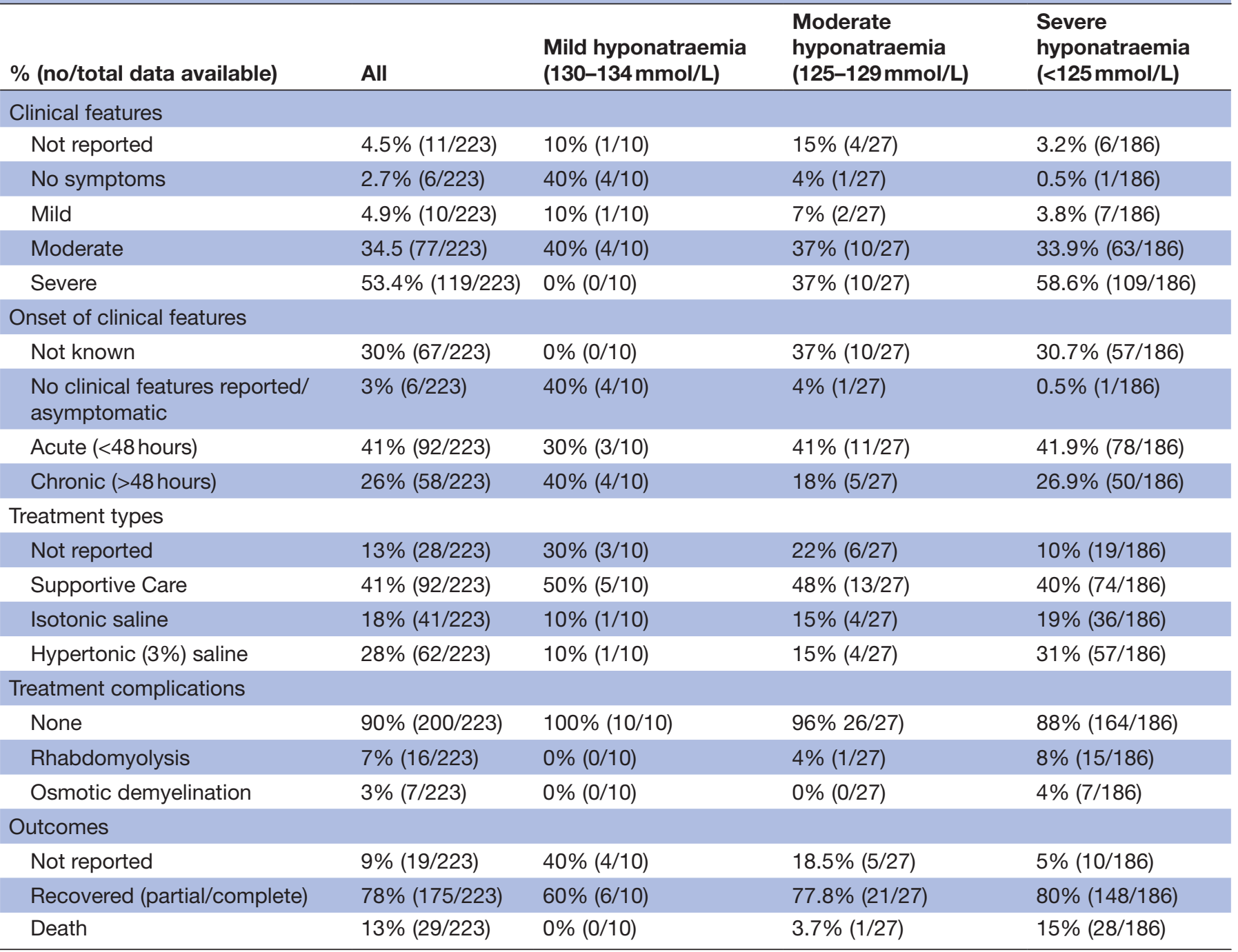




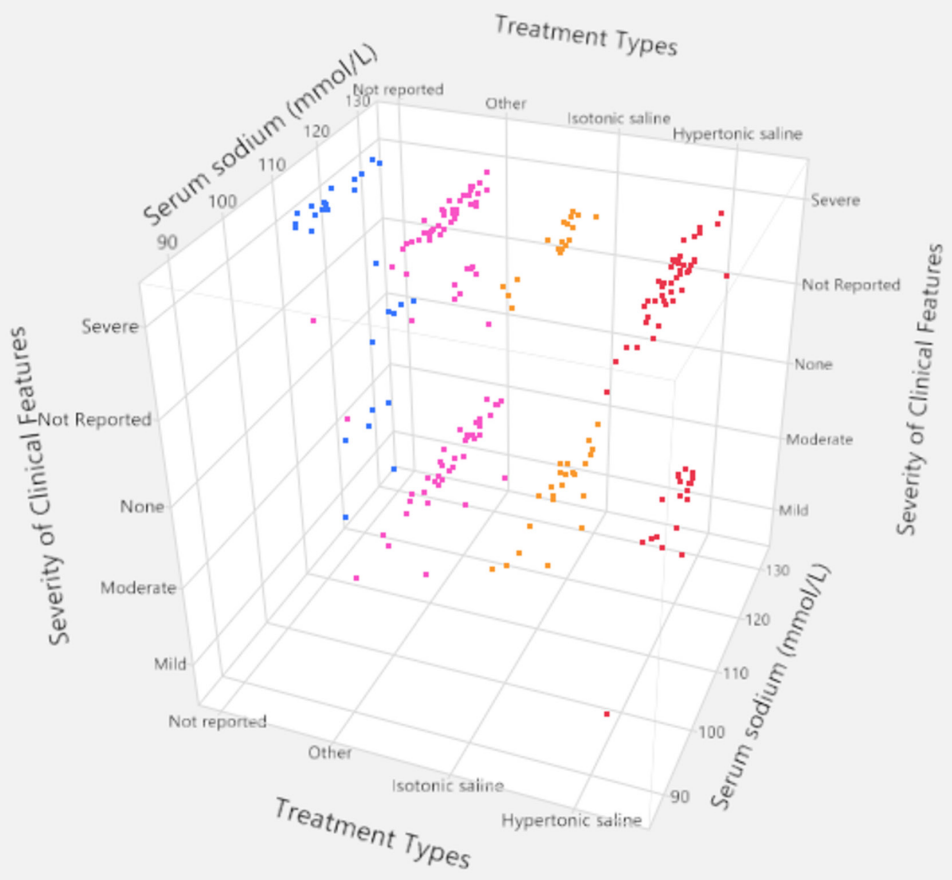

Figure 4 3D scatterplot box to group cases according to serum sodium, treatment type and severity of clinical presentation. Dots are coloured according to treatment type (hypertonic saline, red; isotonic saline, orange; other, pink or not reported, blue). 3D, three dimensions.

In the remainder, the majority recovered $(78 \%)$ and $13 \%$ died (table 5 and figure 5 ). In addition, $11 \%$ of patients remained biochemically hyponatraemic or had recurrent episodes despite treatment. The cause of death was either unknown (10\%), related to hyponatraemia and

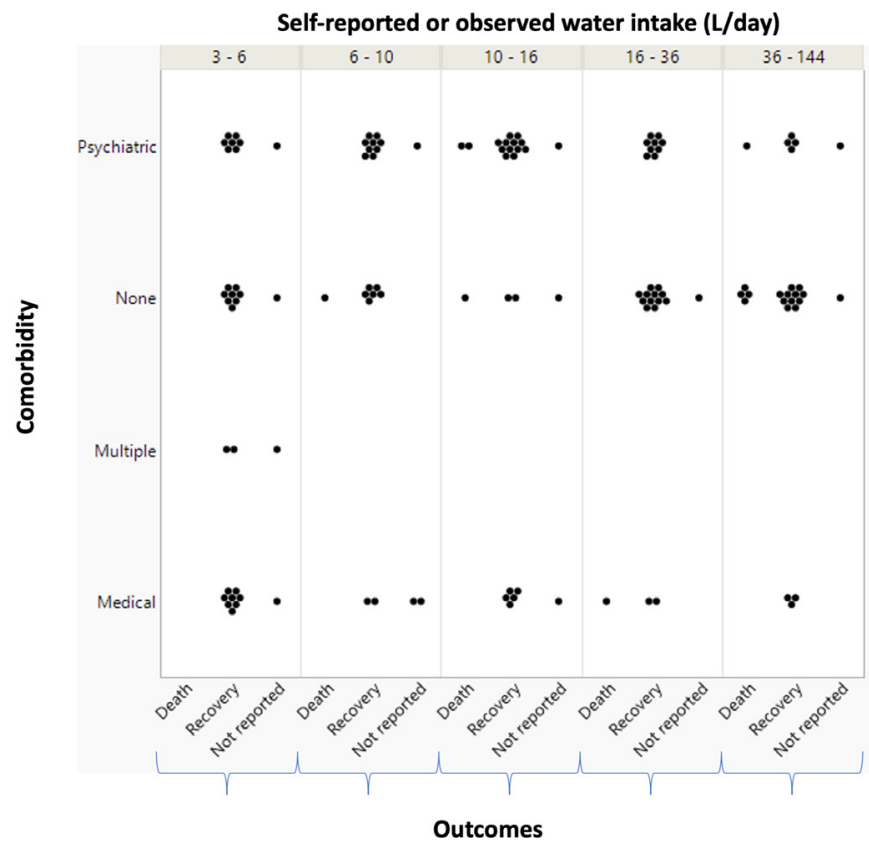

Figure 5 Categorisation of cases according to underlying comorbidities, water intake (litres per day) and outcomes. its associated complications (eg, cerebral and pulmonary oedema or OMD syndrome) $(49 \%)$ or due to other underlying conditions (cancer, pneumonia, cardiac arrest or suicide) $(41 \%)$. Autopsies were conducted in $43 \%$ of patients who died and common signs of water intoxication included an enlarged stomach, duodenum and small intestine; pulmonary/cerebral oedema; a large volume of dilute cadaveric blood and a distended bladder.

\section{DISCUSSION}

The aim of this systematic review was to define the clinical characteristics, treatment patterns and outcomes of excess water intake. The main findings were that: (1) the majority of studies reported that patients had a chronic psychiatric morbidity, primarily schizophrenia spectrum disorders; (2) a significant proportion of cases (41\%) described patients receiving concomitant medications that are associated with hyponatraemia suggesting that multiple factors were involved in the pathogenesis of water intoxication; (3) the reasons for excessive consumption was primary due to psychogenic polydipsia but exercise and iatrogenic factors were involved in some cases; (4) the median water intake that was self-reported or observed by others was $8.0 \mathrm{~L} /$ day and the mean serum sodium was $118 \mathrm{mmol} / \mathrm{L}$; (5) $28 \%$ of patients received hypertonic saline, and treatment-related complications 
and death were reported in $10 \%$ and $13 \%$ of the cases/ case series, respectively.

Water is essential for life and constitutes between $45 \%$ and $75 \%$ of total body weight. ${ }^{205}$ National dietary guidelines recommend the consumption of 'plenty of water, ${ }^{206}$ and adequate intake (AI) is defined as $2.1 \mathrm{~L} /$ day for adult women and $2.6 \mathrm{~L} /$ day for adult men based on the median water intake in the general population. ${ }^{206}$ As water requirements vary widely according to multiple factors (age, gender, comorbidities, activity level, ambient temperate, basal metabolic rate) guidelines do not attempt to define a precise amount that applies to every individual or situation, ${ }^{205} 206$ but rather provide broad guidance on the prevention of complications associated with acute dehydration, and no safe upper limit has been provided. ${ }^{27} 205$ Furthermore, in the general population the majority $(82 \%)$ do not even reach the recommended targets for water consumption ${ }^{207}$ and/or self-regulate their intake, perhaps explaining why water intoxication is a rare event.

In a seminal paper published in 1923, Rowntree was the first to coin the term water intoxication and describe the salient clinical features and pathology of the syndrome in experimental animals as well as recommend hypertonic saline as a treatment. ${ }^{1}$ In humans, one of the fundamental physiological flaws that contributes to water intoxication is that intestinal water absorption exceeds the maximal capacity of the kidney to excrete the load (determined to be between 735 and 970 mls per hour). ${ }^{6}$ While chronic overhydration for more than 3 days leads to adaptive increases in urinary free water excretion (by increasing aquaporin-2 water channel expression in the renal collecting duct ${ }^{208}{ }^{209}$ ) it also elevates renal solute $\operatorname{loss}^{130}$ thereby lowering the threshold for water intoxication. Nevertheless, these homoeostatic mechanisms are overcome by neurobehavioural factors that drive the urge to drink water. ${ }^{28}$ In this regard, it is noteworthy that in mice, isolation and/or anxiety results in habitual polydipsia that reduces dopaminergic neuron excitability of the ventral tegmental area (reward area of the brain) and mediates anxiolytic and/or reward-seeking behaviour. ${ }^{28}$

In the current study, most cases (52\%) suffered from schizophrenia spectrum disorders. Consistent with this finding, in a previous study, $10 \%$ of hospitalised psychiatric inpatients exhibited polydipsia and one-third were at risk of water intoxication. ${ }^{210}$ Remarkably water intoxication was reported as the cause of death in $18.5 \%$ of schizophrenia inpatients under the age of 53 years old. ${ }^{58}$ In our study, compulsive water intake in this population was driven by psychogenic polydipsia probably due to multiple factors including delusional beliefs and anxiety related to an acute psychotic episode; resetting of hypothalamic thirst centres; inappropriate antidiuretic hormone release; urinary solute loss due to chronic overhydration and/or concurrent concomitant medications that predispose to hyponatraemia. ${ }^{142850130135160}$ In addition, other psychiatric disorders linked to water intoxication in our review included chronic anxiety disorder, acute depression and potomania. ${ }^{62} 169174$ Occasionally, some cases of psychogenic polydipsia in this review were not obviously linked to a chronic psychiatric condition. ${ }^{139}$ One example was a 64-year-old woman with mitral valve disease who suddenly began compulsively drinking $30-40$ glasses of water for no apparent reason, leading to cerebral oedema and death. ${ }^{129}$ In this case, it was suspected that the inappropriate behaviour reflected an undiagnosed psychosis ${ }^{139}$ and/or an anxiety disorder. ${ }^{129}$

In this systematic review, we found that exercise was a common predisposing factor for water intoxication, especially in those without a medical or psychiatric condition. ${ }^{6} 1032568892118120133162170186202203$ In support of this finding, a case-control study of 88 participants in the London Marathon found that $12.5 \%(11 / 88)$ developed asymptomatic hyponatraemia (128-134 mmol/L) and that this was related in part to higher fluid intake (3683 mL vs $1924 \mathrm{~mL}) .{ }^{162}$ In addition, in the Hawaiian and New Zealand triathlons biochemical and clinical hyponatraemia was detected in $27 \%$ and $18 \%$ of participants, respectively. ${ }^{211} 212$ Three key factors mediate the pathogenesis of exercise-induced water intoxication ${ }^{213}$ : (1) excessive sodium loss due to prolonged sweating and exercise, as in ultramarathon runners participating in distance running events; (2) aggressive intake of fluid containing low levels of electrolyte solution; and (3) individual variations in thirst perception and levels of habitual water consumption. ${ }^{214}$

Of importance, the present systematic review identified several cases of iatrogenic causes of water intoxication. The cases included medical advice provided to patients by healthcare workers to increase water intake: to prepare for an ultrasound, ${ }^{51} 556469117159172190$ colonoscopy ${ }^{136} 142190198$ or prior to uroflowmetry ${ }^{140}$; prevent haemorrhagic cystitis $^{151}$; during the perioperative period $^{108 ~ 131}$; during labour ${ }^{126}{ }^{204}$; following accidental poisoning ${ }^{49}$; during participation in a research study ${ }^{88}$; to treat a suspected urinary tract infection ${ }^{45}$ and/ or for potential health benefits. ${ }^{86} 180$ In some of these situations, other additional exacerbating factors were identified, such as low dietary solute, ${ }^{198}$ anxiety, ${ }^{131}$ renal impairment, ${ }^{45}$ use of complementary medicines (such as giant leaf frog venom ${ }^{191}$ ); recent introduction of concomitant medications that lower serum sodium (particularly thiazide diuretics or recent use of cyclophosphamide) $)^{134151183}$ or the presence of a urethral stricture. ${ }^{45}$ However, the key factor leading to water intoxication was misinterpretation of the medical advice provided (such as: 'drink plenty of water'; 'as much as you can ${ }^{49}{ }^{69}$ ) and the assumption that drinking more would lead to better outcomes ("the more you drink, the better the test results'. ${ }^{55} 159$ Although iatrogenic polydipsia is probably very rare, these cases highlight the need for healthcare workers to be more specific when providing instructions about the volume and rate of water intake (such as, 'drinking three glasses of water $(750 \mathrm{~mL})$ spread over a period of 2 hours') $)^{108} 117140172$ and to adhere to evidence-based guidelines. ${ }^{180}$ 
Miscellaneous cases of water intoxication identified in this review included anorexia nervosa, ${ }^{112}$ a self-remedy for chronic hiccups, ${ }^{6293123}$ replacing fluids during acute gastroenteritis $^{83109}$ or respiratory tract infection ${ }^{145}$; providing a urine sample for drug testing. ${ }^{10} 128132167$ In the latter case, paruresis (difficulty urinating in public; present in up to $25 \%$ of the general population) may lead to emotion stress and antidiuretic hormone release and lower the threshold for water intoxication. ${ }^{128} 167215 \mathrm{~A}$ notable case of water intoxication was reported in a flight attendant (who commenced on thiazide diuretic 2 weeks prior to presentation) also highlights the synergistic effects of low partial pressure of oxygen (which stimulates antidiuretic hormone release) with workplace advice to maintain in-flight hydration. ${ }^{183}$ As discussed earlier, normal kidney function and urine outflow are essential for preventing water intoxication. This was demonstrated in the case of a 28-year-old man with a urethral stricture who was advised to drink '30-40 glasses of water' over 5 hours to treat a suspected urinary tract infection. ${ }^{45}$

In this systematic review, the median volume of water intake associated with intoxication was $8.0 \mathrm{~L}$ per day or $5.3 \mathrm{~L}$ over 4-hour period. Despite the limitations of this data (in that the volume of water recorded in most case reports was self-reported or observed, rather than actual measurements), it is interesting that this value is similar to the highest percentile (99th) of total water intake in the general population (with $5 \%$ of men consuming $>6.4 \mathrm{~L} /$ day). ${ }^{205}$ In addition, it is also consistent with physiological calculations that an increase of $\sim 5.1 \mathrm{~L}$ of total body water is required to reduce the serum sodium from $140 \mathrm{mmol} / \mathrm{L}$ to severe biochemical hyponatraemia $(125 \mathrm{mmol} / \mathrm{L}){ }^{205}$ However, as shown by the variability of this data between different cases and as discussed earlier, multiple factors (such as concurrent use of medications that lower serum sodium; loss of sodium through sweating during exercise; and/or reduced dietary intake solute) contribute to the volume of water required to develop intoxication.

As might be expected due to the publication bias, this review found that the majority of patients in case reports/ case series (53\%) presented with severe clinical features at presentation (seizures, coma). In addition, more than half $(58 \%)$ the onset was chronic ( $>48$ hours) most likely due to the fact that a high proportion of patients had an underlying chronic psychiatric disorder in this review. The spectrum of clinical features described in this review are all consistent with known features of hyponatraemia but do not provide any specific insights into symptoms associated with mild water intoxication. ${ }^{216}$ In this regard, chronic mild hyponatraemia has been associated with a high incidence of falls in older patients as well as mild cognitive deficits, ${ }^{217} 218$ and in future studies it would important to elucidate the role that excess water intake may contribute to this problem in this population. ${ }^{205}$

Unfortunately, in this study, $13 \%$ of cases reports/ cases series reported that patients died due to water

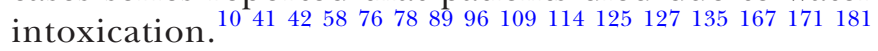
187192193202 In addition, $11 \%$ of those that recovered from the acute episode remained biochemically hyponatraemic or had recurrent episodes despite treatment. The postmortem findings in patients who died were identical to Rowntree's description in experimental animals, describing cerebral oedema and gastric distension. ${ }^{1}$ Because levels of serum electrolytes decrease after death, vitreous humour fluid was used to diagnose hyponatraemia in fatal cases due to its resistance to change post-mortem. ${ }^{135} 171193$

Due to low quality of evidence in this review, it was not possible to make any specific conclusions on the management of water intoxication, such as when and if isotonic or hypertonic saline should be used. Consistent with clinical practice guidelines, ${ }^{216}$ chronic mild hyponatraemia without severe clinical features was typically treated with water restriction alone, but this was often ineffective in psychiatric patients due to non-compliance. ${ }^{84} 156$ To address this, behavioural interventions involving positive reinforcement were trialled to encourage compliance and self-efficacy. ${ }^{84}$ Severe hyponatraemia was treated with a combinations of water restriction, hypertonic saline or isotonic saline. Isotonic saline was used interchangeably, particularly when symptom onset was chronic ( $>48$ hours) or unknown. Three per cent of case reports/case series reported OMD occurring as a complication of rapid correction, and all patients had either chronic or unknown onset of hyponatraemia, consistent with pathogenesis of this condition. ${ }^{219}$ While not directly comparable, it is important to note, that the prevalence of OMD was lower in two retrospective cohorts of patients hospitalised for hyponatraemia $(0.6 \%, 9 / 1490$; and $0 \%, 0 / 56$ patients $),{ }^{220} 221$ indicating that the correction of serum sodium using conservative measures (such as fluid restriction, urea) is appropriate in patients with chronic polydipsia once severe life-threatening complications have been addressed with hypertonic saline. ${ }^{219} 222$ In this review, rhabdomyolysis was reported as rare complication of both water intoxication as well as rapid correction of hyponatraemia. ${ }^{102} 194$ It has been hypothesised that the overcorrection of sodium may lead dysregulation of myocyte cell volume and fragility leading to rhabdomyolysis. ${ }^{194}$

There were several limitations in this systematic review. First, most of the data were derived from case reports or case series of severe clinical cases of water intoxication, and the characteristics of milder cases have not been captured. Furthermore, for this reason the true population-based prevalence of water intoxication cannot be determined from the data in this study. Second, the hetereogenity in reporting the volume of water consumed as well as the exposure time, and the inclusion of self-reported or observed volumes in the absence of standardised method reduces the precision of this estimate. Third, 'total fluid intake' was assumed to consist of plain water though this may not have been the case. Fourth, data were incomplete in up to 5\%-30\% of studies. Finally, other rare long-term 
complications of excessive fluid intake (obstructive uropathy leading to renal impairment, cardiac failure, gastrointestinal dilatation, osteopenia with increased fracture risk) were not assessed in this systematic review. ${ }^{523}$

In summary, severe water intoxication is a rare syndrome but hospitalisation and healthcare utilisation as well as morbidity and mortality may be a common outcome. An underlying chronic psychiatric condition $(52 \%)$ causing psychogenic polydipsia was the most frequent clinical factor involved, whereas in otherwise healthy individuals, exercise, iatrogenic, habitual/dipsogenic-associated polydipsia accounted for $33 \%$ of reported cases. Moreover, the median water consumption was much higher than population-based recommendations and consistent with physiological values suspected with the risk of harm. ${ }^{205} 206$ The results of this review findings provide evidence regarding the potential dangers of overhydration and remind healthcare practitioners to be vigilant about providing clear and specific education regarding water intake to patients, especially in those that might be susceptible to misunderstanding this information.

\section{Author affiliations}

${ }^{1}$ Michael Stern Laboratory for Polycystic Kidney Disease, Westmead Institute for Medical Research, Westmead, New South Wales, Australia

${ }^{2}$ Department of Renal Medicine, Westmead Hospital, Westmead, New South Wales, Australia

${ }^{3}$ School of Life and Environmental Sciences, The University of Sydney, Camperdown, New South Wales, Australia

${ }^{4}$ Nutrition and Dietetics, Faculty of Medicine and Health, The University of Sydney, Sydney, New South Wales, Australia

${ }^{5}$ School of Public Health, The University of Sydney, Sydney, New South Wales, Australia

Acknowledgements The authors thank Ms Monica Cooper, University of Sydney Library for advice and support in developing the search criteria and performing data extraction.

Contributors GKR conceived the idea for the project, extensively revised the initial version of the manuscript for intellectual content, checked, recoded the data and performed data analysis, resubmitted the revised manuscript; ND and MMZ contributed to drafting sections of the first version of the manuscript, performed the data collection, developed search terms, extracted and analysed data with the guidance of GKR and AW; LA-Z and HCL cross-checked and interpreted the data, AW and AR contributed to editing for intellectual content, interpretation of data and overall project oversight and supervision with GKR; AM submitted the first version of the manuscript, contributed to editing for intellectual content and interpretation of the data; AC, SS and JQJZ contributed to editing for intellectual content and interpretation of data. MH provided expertise on systematic review analysis, contributed to editing for intellectual content and interpretation of data. All authors approved the final version of the manuscript, accept full responsibility for the work, conduct of the study and controlled the decision to publish. GR, LA-Z and HCL had access to the data.

Funding This study received no specific funding. GKR is a full-time employee of Westmead Hospital (Western Sydney Local Health District, NSW Health) and all facilities to produce this manuscript were provided by the Westmead Institute for Medical Research, The University of Sydney. AW, AM and SS are supported by project grants from the National Health and Medical Research Council of Australia (Grant Nos. 1138533 and 1164128) and in part an investigator-initiated grant from PKD Australia (no grant number is provided for this award). JQJZ and AC are supported by a Research Training Programme Stipend from the University of Sydney (no grant number is provided for this award). The manuscript was prepared was independently of the funding organisations.
Competing interests GKR is chief investigator of an investigator-initiated grant from Danone Nutricia, but this project was conducted independently of this work. All other authors have no other relevant affiliations or financial involvement with any organisation or entity with a financial interest in or financial conflict with the subject matter or materials discussed in the manuscript apart from those disclosed.

Patient consent for publication Not applicable.

Ethics approval This study was a systematic review based on literature that is publicly available. All material in the published articles were de-identified. The study is a not a clinical study and therefore approval from a Human Research was not required. The systematic review was prospectively registered in the International Prospective Register of Systematic Reviews (PROSPERO).

Provenance and peer review Not commissioned; externally peer reviewed.

Data availability statement All data relevant to the study are included in the article or uploaded as online supplemental information.

Supplemental material This content has been supplied by the author(s). It has not been vetted by BMJ Publishing Group Limited (BMJ) and may not have been peer-reviewed. Any opinions or recommendations discussed are solely those of the author(s) and are not endorsed by BMJ. BMJ disclaims all liability and responsibility arising from any reliance placed on the content. Where the content includes any translated material, BMJ does not warrant the accuracy and reliability of the translations (including but not limited to local regulations, clinical guidelines, terminology, drug names and drug dosages), and is not responsible for any error and/or omissions arising from translation and adaptation or otherwise.

Open access This is an open access article distributed in accordance with the Creative Commons Attribution Non Commercial (CC BY-NC 4.0) license, which permits others to distribute, remix, adapt, build upon this work non-commercially, and license their derivative works on different terms, provided the original work is properly cited, appropriate credit is given, any changes made indicated, and the use is non-commercial. See: http://creativecommons.org/licenses/by-nc/4.0/.

\section{ORCID iDs}

Alexandra Munt http://orcid.org/0000-0002-9049-1821

Martin Howell http://orcid.org/0000-0001-9740-712X

\section{REFERENCES}

1 Rowntree LG. Water intoxication. Can Med Assoc J 1923;13:157-74.

2 Barahal HS. Water intoxication in a mental case. Psychiatr $Q$ 1938;12:767-71.

3 Sterns RH. Disorders of plasma sodium-causes, consequences, and correction. N Engl J Med 2015;372:55-65.

4 Verbalis JG, Goldsmith SR, Greenberg A, et al. Diagnosis, evaluation, and treatment of hyponatremia: expert panel recommendations. Am J Med 2013;126:S1-42.

5 Sailer CO, Winzeler B, Nigro N, et al. Characteristics and outcomes of patients with profound hyponatraemia due to primary polydipsia. Clin Endocrinol 2017;87:492-9.

6 Noakes TD, Wilson G, Gray DA, et al. Peak rates of diuresis in healthy humans during oral fluid overload. S Afr Med J 2001;91:852-7.

7 Armed Forces Health Surveillance, B. Update: exertional hyponatremia, active component, U.S. armed forces, 2001-2016. MSMR 2017;24:19-24.

8 Jose CJ, Perez-Cruet J. Incidence and morbidity of self-induced water intoxication in state mental hospital patients. Am J Psychiatry 1979;136:221-2.

9 Gleadhill IC, Smith TA, Yium JJ. Hyponatremia in patients with schizophrenia. South Med J 1982;75:426-8.

10 Gardner JW, Gardner JW. Death by water intoxication. Mil Med 2002;167:432-4.

11 Chamberlain L. Hyponatremia caused by polydipsia. Crit Care Nurse 2012;32:e11-20.

12 Rosner MH, Kirven J. Exercise-associated hyponatremia. Clin J Am Soc Nephrol 2007;2:151-61.

13 Lee LC, Noronha M. When plenty is too much: water intoxication in a patient with a simple urinary tract infection. BMJ Case Rep 2016:01.

14 Liamis G, Milionis H, Elisaf M. A review of drug-induced hyponatremia. Am J Kidney Dis 2008;52:144-53.

15 Lum G. Severe hyponatremia in a schizophrenic patient. Clin Chem 2013;59:887-9. 
16 Kotagiri R, Kutti Sridharan G. Primary polydipsia, in StatPearls. Treasure Island (FL: National Center for Biotechnology Information, 2021.

17 Sailer C, Winzeler B, Christ-Crain M. Primary polydipsia in the medical and psychiatric patient: characteristics, complications and therapy. Swiss Med Wkly 2017;147:w14514.

18 Valtin H. "Drink at least eight glasses of water a day." Really? Is there scientific evidence for "8 × 8"? Am J Physiol Regul Integr Comp Physiol 2002;283:R993-1004.

19 Goldman MB, Luchins DJ, Robertson GL. Mechanisms of altered water metabolism in psychotic patients with polydipsia and hyponatremia. N Engl J Med 1988;318:397-403.

20 Rowe JW, Kilgore A, Robertson GL. Evidence in man that cigarette smoking induces vasopressin release via an airway-specific mechanism. J Clin Endocrinol Metab 1980;51:170-2.

21 Blum A. The possible role of tobacco cigarette smoking in hyponatremia of long-term psychiatric patients. JAMA 1984:252:2864-5.

22 Torres VE, Bankir L, Grantham JJ. A case for water in the treatment of polycystic kidney disease. Clin J Am Soc Nephrol 2009;4:1140-50.

23 Naumann J, Biehler D, Lüty T, et al. Prevention and therapy of type 2 Diabetes-What is the potential of daily water intake and its mineral nutrients? Nutrients 2017;9. doi:10.3390/nu9080914. [Epub ahead of print: 22 Aug 2017].

24 Wagner S, Merkling T, Metzger M, et al. Water intake and progression of chronic kidney disease: the CKD-REIN cohort study. Nephrol Dial Transplant 2021. doi:10.1093/ndt/gfab036. [Epub ahead of print: 12 Feb 2021]

25 Wong ATY, Mannix C, Grantham JJ, et al. Randomised controlled trial to determine the efficacy and safety of prescribed water intake to prevent kidney failure due to autosomal dominant polycystic kidney disease (PREVENT-ADPKD). BMJ Open 2018;8:e018794.

26 Scales CD, Desai AC, Harper JD, et al. Prevention of urinary stones with hydration (push): design and rationale of a clinical trial. Am J Kidney Dis 2021;77:898-906.

27 McCotter L, Douglas P, Laur C, et al. Hydration education: developing, piloting and evaluating a hydration education package for general practitioners. BMJ Open 2016;6:e012004.

28 Hew-Butler T, Smith-Hale V, Pollard-McGrandy A, et al. Of mice and Men-The physiology, psychology, and pathology of Overhydration. Nutrients 2019;11. doi:10.3390/nu11071539. [Epub ahead of print: 07 Jul 2019].

29 Moher D, Liberati A, Tetzlaff J, et al. Preferred reporting items for systematic reviews and meta-analyses: the PRISMA statement. BMJ 2009;339:b2535.

30 Boland A, Cherry G, Dickson R. Doing a systematic review. Second ed. Liverpool, United Kingdom: Sage Publishing, 2017.

31 Sadock BJ, Sadock VA, Ruiz P. Synopsis of psychiatry. 11th ed. Philadelphia, USA: Wolters Kluwer, 2015.

32 Oh RC, Malave B, Chaltry JD. Collapse in the heat - from overhydration to the emergency room - three cases of exerciseassociated hyponatremia associated with exertional heat illness. Mi Med 2018;183:e225-8.

33 Murad MH, Sultan S, Haffar S, et al. Methodological quality and synthesis of case series and case reports. BMJ Evid Based Med 2018;23:60-3

34 et alWells GA, Shea B, O'Connell D. The Newcastle-Ottawa scale (NOS) for assessing the quality of nonrandomised studies in metaanalyses, 2014. Available: http://www.ohri.ca/programs/clinical_ epidemiology/oxford.asp

35 Beresford HR. Polydipsia, hydrochlorothiazide, and water intoxication. JAMA 1970;214:879-83.

36 Raskind M. Psychosis, polydipsia, and water intoxication. Report of a fatal case. Arch Gen Psychiatry 1974;30:112-4.

37 Worthley LI. Rapid correction of water intoxication by hypertonic saline and frusemide. Aust N Z J Med 1975;5:557-60.

38 Rae J. Self-Induced water intoxication in a schizophrenic patient. Can Med Assoc J 1976;114:438-9.

39 Noonan JP, Ananth J. Compulsive water drinking and water intoxication. Compr Psychiatry 1977;18:183-7.

40 Rosenbaum JF, Rothman JS, Murray GB. Psychosis and water intoxication. Journal of Clinical Psychiatry 1979;40:287-91.

41 DiMaio VJ, DiMaio SJ. Fatal water intoxication in a case of psychogenic polydipsia. J Forensic Sci 1980;25:12131J-5.

42 Hariprasad MK, Eisinger RP, Nadler IM, et al. Hyponatremia in psychogenic polydipsia. Arch Intern Med 1980;140:1639-42.

43 Shevitz SA, Jameison RC, Petrie WM, et al. Compulsive water drinking treated with high dose propranolol. J Nerv Ment Dis 1980;168:246-8.
44 Nixon RA, Rothman JS, Chin W. Demeclocycline in the prophylaxis of self-induced water intoxication. Am J Psychiatry 1982;139:828-30.

45 Friedman E, Hanany J, Halkin H. Unsuspected urethral stricture presenting as acute water intoxication. J Urol 1983;130:566.

46 Howe JG, Penney MD, Currie S, et al. Thirst, resetting of the osmostat, and water intoxication following encephalitis. Ann Neurol 1983;13:201-4.

47 Emsley RA, Gledhill RF. Thiazides, compulsive water drinking and hyponatraemic encephalopathy. J Neurol Neurosurg Psychiatry 1984;47:886-7.

48 Gillum DM, Linas SL. Water intoxication in a psychotic patient with normal renal water excretion. Am J Med 1984;77:773-4.

49 Sarvesvaran R. Dilute the Poison-A case of fatal water intoxication. Med Sci Law 1984;24:92-4.

50 Vieweg WVR, ROWE WT, DAVID JJ, et al. Evaluation of patients with self-induced water intoxication and schizophrenic disorders (SIWIS). J Nerv Ment Dis 1984;172:552-5.

51 Christenson LL, Scott D. Acute water intoxication following pelvic ultrasound examination. Postgrad Med 1985;77:161-2.

52 De Soto MF, Griffith SR, Katz EJ. Water intoxication associated with nephrogenic diabetes insipidus secondary to lithium: case report. $J$ Clin Psychiatry 1985;46:402-3.

53 Goldman MB, Luchins DJ. Demeclocycline improves hyponatremia in chronic schizophrenics. Biol Psychiatry 1985;20:1149-55.

54 Inoue K, Tadai T, Kamimura $\mathrm{H}$, et al. The syndrome of self-induced water intoxication in psychiatric patients. Folia Psychiatr Neurol Jpn 1985;39:121-8

55 Kott E, Marcus Y. Acute brain edema due to water loading in a young woman. Eur Neurol 1985;24:221-4.

56 Noakes TD, Goodwin N, Rayner BL, et al. Water intoxication: a possible complication during endurance exercise. Med Sci Sports Exerc 1985;17:370-5.

57 Shesser R, Smith M. Seizures in psychiatric patients. Am J Emerg Med 1985;3:451-5.

58 Vieweg WV, David JJ, Rowe WT, et al. Death from self-induced water intoxication among patients with schizophrenic disorders. $J$ Nerv Ment Dis 1985;173:161-5.

59 Vieweg WV, Rowe WT, David JJ, et al. Oral sodium chloride in the management of schizophrenic patients with self-induced water intoxication. J Clin Psychiatry 1985;46:16-19.

60 Kathol RG, Wilcox JA, Turner RD, et al. Pharmacologic approaches to psychogenic polydipsia: case reports. Prog Neuropsychopharmacol Biol Psychiatry 1986;10:95-100.

61 Ledochowski M, Kahler M, Dienstl F, et al. Water intoxication in the course of an acute schizophrenic episode. Intensive Care Med 1986;12:47-8.

62 Cronin RE. Psychogenic polydipsia with hyponatremia: report of eleven cases. Am J Kidney Dis 1987;9:410-6.

63 Fleischhacker WW, Barnas C, Ledochowski M. HyponatremiaInduced organic mental disorder may mask paranoid schizophrenia. Biol Psychiatry 1987;22:650-2.

64 Lipsky MS, Zabak DL. Hyponatremia resulting from pelvic ultrasound preparation. J Fam Pract 1987;25:216-7.

65 Mor F, Mor-Snir I, Wysenbeek AJ. Rhabdomyolysis in self-induced water intoxication. J Nerv Ment Dis 1987:175:742-3.

66 Yonemura $\mathrm{K}$, Hishida A, Miyajima $\mathrm{H}$, et al. Water intoxication due to excessive water intake: observation of initiation stage. Jpn J Med 1987;26:249-52.

67 Young M, Sciurba F, Rinaldo J. Delirium and pulmonary edema after completing a marathon. Am Rev Respir Dis 1987;136:737-9.

68 Prim RG. Water intoxication and psychosis syndrome. Clinical cautions. J Psychosoc Nurs Ment Health Serv 1988;26:16-18.

69 Shapira I, Isakov A, Almog C. Hyponatremia as the result of preparation for abdominal ultrasound examination. $J$ Clin Ultrasound 1988;16:61-2.

70 Finlayson AJ, Vieweg WV, Wilkey WD, et al. Hyponatremic seizure following ECT. Can J Psychiatry 1989;34:463-4.

71 Koczapski AB, Millson RC. Individual differences in serum sodium levels in schizophrenic men with self-induced water intoxication. Am J Psychiatry 1989;146:1614-5.

72 Ripley TL, Millson RC, Koczapski AB. Self-Induced water intoxication and alcohol abuse. Am J Psychiatry 1989;146:102-3.

73 Tallis GA. Hyponatraemia in psychiatric patients. Med J Aust 1989;150:151-3.

74 Allon M, Allen HM, Deck LV, et al. Role of cigarette use in hyponatremia in schizophrenic patients. Am J Psychiatry 1990;147:1075-7.

75 Cheng JC, Zikos D, Skopicki HA, et al. Long-Term neurologic outcome in psychogenic water drinkers with severe symptomatic hyponatremia: the effect of rapid correction. Am J Med 1990;88:561-6. 
76 Cosgray RE, Hanna V, Davidhizar RE, et al. The water-intoxicated patient. Arch Psychiatr Nurs 1990;4:308-12.

77 el-Mallakh RS, Cearnal LR, Kirch DG. Stereotypic behavior and hyponatremia. Biol Psychiatry 1990;28:1077-8.

78 Kushnir M, Schattner A, Ezri T, et al. Schizophrenia and fatal selfinduced water intoxication with appropriately-diluted urine. $\mathrm{Am} \mathrm{J}$ Med Sci 1990;300:385-7.

79 Peh LH, Devan GS, Eu PW. Water intoxication in psychiatric patients in Singapore. Singapore Med J 1990;31:238-41.

80 Peh LH, Devan GS, Low BL. A fatal case of water intoxication in a schizophrenic patient. British Journal of Psychiatry 1990;156:891-4.

81 Bremner AJ, Regan A. Intoxicated by water. polydipsia and water intoxication in a mental handicap Hospital. British Journal of Psychiatry 1991;158:244-50.

82 Grainger DN. Rapid development of hyponatraemic seizures in a psychotic patient. Psychol Med 1992;22:513-7.

83 Moskowitz DW. Functional obstructive uropathy: a significant factor in the hyponatremia of psychogenic polydipsia? J Urol 1992;147:1611-3.

84 Pavalonis D, Shutty M, Hundley P, et al. Behavioral intervention to reduce water intake in the syndrome of psychosis, intermittent hyponatremia, and polydipsia. J Behav Ther Exp Psychiatry 1992;23:51-7.

85 Shah PJ, Greenberg WM. Polydipsia with hyponatremia in a state hospital population. Hosp Community Psychiatry 1992;43:509-11.

86 Woodard PK, Gitelman HJ. Syndrome of 'iatrogenic' polydipsia. Am Fam Physician 1992;46:374.

87 Akasaki Y, Nagatomo I, Akasaki Y, et al. Water intoxication in a schizophrenic patient with rhabdomyolysis. Psychiatry Clin Neurosci 1993;47:843-6.

88 Armstrong LE, Curtis WC, Hubbard RW, et al. Symptomatic hyponatremia during prolonged exercise in heat. Med Sci Sports Exerc 1993;25:543-9.

89 Cosgray R, Davidhizar R, Giger JN, et al. A program for waterintoxicated patients at a state Hospital. Clin Nurse Spec 1993;7:55-61.

90 Ellinas PA, Rosner F, Jaume JC. Symptomatic hyponatremia associated with psychosis, medications, and smoking. J Natl Med Assoc 1993;85:135-41.

91 Kruse DH. A 54-year-old man with hiccoughs. J Emerg Nurs 1993;19:471-2.

92 Putterman C, Levy L, Rubinger D. Transient exercise-induced water intoxication and rhabdomyolysis. Am J Kidney Dis 1993;21:206-9.

93 Ramirez FC, Graham DY. Hiccups, compulsive water drinking, and hyponatremia. Ann Intern Med 1993;118:649.

94 Shutty MS, Leadbetter RA. Case report: recurrent pseudocyesis in a male patient with psychosis, intermittent hyponatremia, and polydipsia. Psychosom Med 1993;55:146-8.

95 Tanneau RSet al. Prognosis and neurologic outcome of severe hyponatremia in elderly patients. European Journal of Internal Medicine 1993;4:311-8.

96 Goldman MB. Moderate hyponatremia and death in a polydipsic schizophrenic on lithium. Biol Psychiatry 1994;36:485-6.

97 Goldman MB, Nash M, Blake L, et al. Do electrolyte-containing beverages improve water imbalance in hyponatremic schizophrenics? J Clin Psychiatry 1994;55:151-3.

98 Lyster C, Miller AL, Seidel D, et al. Polydipsia and clozapine. Hosp Community Psychiatry 1994;45:610-a-1.

99 de Leon J, Verghese C, Stanilla JK, et al. Treatment of polydipsia and hyponatremia in psychiatric patients. can clozapine be a new option? Neuropsychopharmacology 1995;12:133-8.

100 Looi JCL, Cubis JC, Saboisky J. Hyponatremia, convulsions and neuroleptic malignant syndrome in a male with schizoaffective disorder. Aust N Z J Psychiatry 1995;29:683-7.

101 Primavera A, Fonti A, Giberti L, et al. Recurrent absence status epilepticus and hyponatremia in a patient with polydipsia. Biol Psychiatry 1995;38:189-91.

102 Korzets A, Ori Y, Floro S, et al. Case report: severe hyponatremia after water intoxication: a potential cause of rhabdomyolysis. Am J Med Sci 1996;312:92-4.

103 Shiwach RS. Hyponatremia from colonic lavage presenting as an acute confusional state. Am J Psychiatry 1996;153:1367.

104 Chong S-A, Tan L-L, Wong M-C, et al. Disordered water homeostasis in Asian patients with schizophrenia. Aust N Z J Psychiatry 1997;31:869-73.

105 Hanihara T, Amagai I, Hagimoto $\mathrm{H}$, et al. Hypouricemia in chronic schizophrenic patients with polydipsia and hyponatremia. J Clin Psychiatry 1997;58:256-60.

106 Issa MM, Pruthi RS, Vial C, et al. An unusual complication following uroflowmetry: water intoxication resulting in hyponatremia and seizure. Urol Int 1997;59:129-30.
107 Itoh N, Fuwano S, Matsui N, et al. Reduction of hyponatremia in a schizophrenic with polydipsia-hyponatremia syndrome by surgical intervention. Psychiatry Res 1997;70:125-9.

108 Olapade-Olaopa EO, Morley RN, Ahiaku EK, et al. latrogenic polydipsia: a rare cause of water intoxication in urology. $\mathrm{Br} \mathrm{J}$ Urol 1997;79:488.

109 Sjøblom E, Højer J, Ludwigs U, et al. Fatal hyponatraemic brain oedema due to common gastroenteritis with accidental water intoxication. Intensive Care Med 1997;23:348-50.

110 Ligtenberg JJ, Wymenga AN, Tulleken JE, et al. A lethal complication of psychogenic polydipsia: cerebral edema and herniation. Intensive Care Med 1998:24:644-5.

111 Mercier-Guidez E. Psychiatric patients and water intoxication: implications for diagnosis and treatment. Intensive Care Med 1998;24:643-4.

112 Santonastaso P, Sala A, Favaro A. Water intoxication in anorexia nervosa: a case report. Int J Eat Disord 1998;24:439-42.

113 Wicki J, Rutschmann OT, Burri H, et al. Rhabdomyolysis after correction of hyponatremia due to psychogenic polydipsia possibly complicated by clozapine. Ann Pharmacother 1998;32:892-5

114 Garigan TP, Ristedt DE. Death from hyponatremia as a result of acute water intoxication in an army basic trainee. Mil Med 1999;164:234-8.

115 Basnyat B, Sleggs J, Spinger M. Seizures and delirium in a trekker: the consequences of excessive water drinking? Wilderness Environ Med 2000;11:69-70.

116 Goldman MB. Effect of adjunctive cortisol on serum sodium in a polydipsic hyponatremic schizophrenic patient. Prog Neuropsychopharmacol Biol Psychiatry 2000;24:233-9.

117 Gopal S, Blum A. latrogenic hyponatremic seizures after routine pelvic ultrasonic imaging. J Am Board Fam Pract 2000;13:451-4.

118 Speedy DB, Noakes TD, Rogers IR, et al. A prospective study of exercise-associated hyponatremia in two ultradistance triathletes. Clin J Sport Med 2000;10:136-41.

119 Caputo F, Marchi G, Coralli B, et al. Symptomatic hypotonic hyponatremia in an alcoholic polydipsic patient: a favourable clinical outcome after slow sodium correction. Alcologia 2001;13:43-6.

120 Davis DP, Videen JS, Marino A, et al. Exercise-associated hyponatremia in marathon runners: a two-year experience. $J$ Emerg Med 2001:21:47-57.

121 O'Brien KK, Montain SJ, Corr WP, et al. Hyponatremia associated with overhydration in U.S. Army trainees. Mil Med 2001;166:405-10.

122 Onozaki A, Suzuki H, Imamura N, et al. Congenital nephrogenic diabetes insipidus with marked hyponatremia. Clin Exp Nephrol 2001;5:265-7.

123 Thoma JL, Howe J, Gaudet A et al. Behavioral treatment of chronic psychogenic polydipsia with hyponatremia: a unique case of polydipsia in a primary care patient with intractable hiccups. $J$ Behav Ther Exp Psychiatry 2001;32:241-50.

124 Tolan P, O'Loughlin D, Botha J. Can seizures and rhabdomyolysis be a potentially serious complication of hyponatremia due to polydipsia? Aust N Z J Psychiatry 2001;35:386.

125 Gutmann FD, Gardner JW. Fatal water intoxication of an army trainee during urine drug testing. Mil Med 2002;167:435-7.

126 Johansson S, Lindow S, Kapadia $\mathrm{H}$, et al. Perinatal water intoxication due to excessive oral intake during labour. Acta Paediatr 2002;91:811-4

127 Budisavljevic MN, Stewart L, Sahn SA, et al. Hyponatremia associated with 3,4-methylenedioxymethylamphetamine ("Ecstasy") abuse. Am J Med Sci 2003;326:89-93.

128 Diamond A, Varshney M. Self induced water intoxication associated with routine employment drug screen leading to symptomatic hyponatremia: a case report. The Internet Journal of Family Practice 2003;3:1-4.

129 Farrell DJ, Bower L. Fatal water intoxication. J Clin Pathol 2003:56:803-a-4

130 Musch W, Xhaet O, Decaux G. Solute loss plays a major role in polydipsia-related hyponatraemia of both water drinkers and beer drinkers. QJM 2003:96:421-6.

131 Bhananker SM, Paek R, Vavilala MS. Water intoxication and symptomatic hyponatremia after outpatient surgery. Anesth Analg 2004:98:1294-6.

132 Finkel KW. Water intoxication presenting as a suspected contaminated urine sample for drug testing. South Med J 2004;97:611-3.

133 Noakes TD, Sharwood K, Collins M, et al. The dipsomania of great distance: water intoxication in an Ironman triathlete. $\mathrm{Br} J$ Sports Med 2004;38:E16.

134 Weiss G. Non-psychogenic polydipsia with hyponatremia. The Internet Journal of Nephrology 2004;2:1-10. 
135 Hayashi T, Ishida Y, Miyashita T, et al. Fatal water intoxication in a schizophrenic patient--an autopsy case. J Clin Forensic Med 2005;12:157-9.

136 Hsu Y-J, Chiu J-S, Lu K-C, et al. Biochemical and etiological characteristics of acute hyponatremia in the emergency department. J Emerg Med 2005;29:369-74.

137 Lydakis C, Apostolakis S, Thalassinos E, et al. Pip syndrome: a potentially threatening manifestation of a psychiatric disorder. Int $J$ Clin Pract 2005;59:612-3.

138 Mavragani CP, Vlachoyiannopoulos PG. Is polydipsia sometimes the cause of oxcarbazepine-induced hyponatremia? Eur J Intern Med 2005;16:296-7.

139 Mukherjee S, Antonarakis ES, Asaduzzaman S, et al. Acute psychological stress-induced water intoxication. Int J Psychiatry Clin Pract 2005:9:142-4.

140 Vishwajeet S, Aneesh S. Water intoxication leading to hyponatremia and seizures: a rare complication of uroflowmetry. Int Urol Nephrol 2005;37:275-6.

141 Zaidi AN. Rhabdomyolysis after correction of hyponatremia in psychogenic polydipsia possibly complicated by ziprasidone. Ann Pharmacother 2005;39:1726-31.

142 Chen HC, Chen CC, Chu P, et al. Acute hyponatremic encephalopathy after preparation of colonoscopy. Journal of Medical Sciences 2006;26:33-6.

143 Tényi T, Vörös V. Successful switch to olanzapine after rhabdomyolysis caused by water intoxication and clozapine use. Pharmacopsychiatry 2006;39:157-8.

144 Hiramatsu R, Takeshita A, Taguchi M, et al. Symptomatic hyponatremia after voluntary excessive water ingestion in a patient without psychiatric problems. Endocr J 2007;54:643-5.

145 Iwazu Y, Honma S, Fujisawa G, et al. Hyponatremic seizure associated with acute respiratory infection. Clin Exp Nephrol 2007;11:230-4.

146 Porter RWJ, Poyser NJ, Briggs PF. A life threatening event from poorly managed dental pain--a case report. Br Dent $J$ 2007;202:203-6.

147 Simmons BB, Haines C. Hyponatremia in an elderly woman: making a bedside diagnosis. Clinical Geriatrics 2007;15:31-4.

148 Strachan P, Prisco D, Multz AS. Recurrent rhabdomyolysis associated with polydipsia-induced hyponatremia - a case report and review of the literature. Gen Hosp Psychiatry 2007;29:172-4.

149 Algahtani HA, Attar AA, Young GB, et al. Central pontine myelinolysis due to rapid correction of hyponatremia induced by excessive water intake. Neurosciences 2008;13:296-8.

150 Chapman TH, Hamilton M. Water intoxication presenting as maternal and neonatal seizures: a case report. $J$ Med Case Rep 2008;2:2.

151 Kato A, Sugiura T, Yamamoto T, et al. Water intoxication induced by low-dose oral cyclophosphamide in a patient with anti-neutrophil cytoplasmic antibody-related glomerulonephritis. NDT Plus 2008;1:286-8.

152 Santos-Soares PC, Bacellar A, Povoas HP, et al. Excessive water ingestion and repeated seizures: the domino effect. Arq Neuropsiquiatr 2008;66:552-3.

153 Snell DM, Bartley C. Osmotic demyelination syndrome following rapid correction of hyponatraemia. Anaesthesia 2008;63:92-5.

154 Chondrogiannis KD, Melemeni A, Staikou C, et al. Perioperative management of a patient with hyponatraemia due to excessive water consumption. Eur J Anaesthesiol 2009;26:711-3.

155 Ismail Z, Syms J, Blumberger D, et al. Varenicline induced polydipsia and hyponatremia in a patient with schizophrenia. Schizophr Res 2010;119:268.

156 Katsarou A, Singh S. Hyponatraemia associated rhabdomyolysis following water intoxication. BMJ Case Rep 2010;2010:bcr0220102720.

157 McDaniel WW, Spiegel DR. Hyponatremia and abnormal ingestion of water in catatonia. Primary Psychiatry 2010;17:29-34.

158 Nardone R, McCoy M, Kunz AB, et al. Hyponatremic encephalopathy mimicking hypoxic-ischemic encephalopathy. Clin Neuroradiol 2010;20:243-6.

159 Yalcin-Cakmakli G, Karli Oguz K, Shorbagi A, et al. Hyponatremic encephalopathy after excessive water ingestion prior to pelvic ultrasound: neuroimaging findings. Intern Med 2010;49:1807-11.

160 Zilles D, Hasan A, Gruber O, et al. Acute polydipsia and water intoxication in first episode schizophrenia. Aust N Z J Psychiatry 2010;44:489.

161 Funayama M, Hisamatsu T, Koreki A. Central pontine demyelinolysis following water intoxication in schizophrenia. Schizophr Res 2011;125:300-1.
162 Kipps C, Sharma S, Tunstall Pedoe D. The incidence of exerciseassociated hyponatraemia in the London marathon. $\mathrm{Br} J$ Sports Med 2011;45:14-19.

163 Lin C-K, Feng Y-T. Polydipsia-induced hyponatremia and status epilepticus in a schizophrenia patient: a case report from the emergency department. Tzu Chi Med J 2011;23:20-2.

164 Phull J, Davies S. Life-threatening hyponatraemia and intramuscular olanzapine: the world's longest therapeutic trial. Case Rep Child Meml Hosp Chic 2011;2011:bcr0820114671.

165 Rao N, Venkatasubramanian G, Korpade V, et al. Risperidone treatment for polydipsia and hyponatremia in schizophrenia: a case report. Turk Psikiyatri Derg 2011;22:123-5.

166 Takagi S, Watanabe Y, Imaoka T, et al. Treatment of psychogenic polydipsia with acetazolamide: a report of 5 cases. Clin Neuropharmacol 2011;34:5-7.

167 Tilley MA, Cotant CL. Acute water intoxication during military urine drug screening. Mil Med 2011;176:541-453.

168 Whitchurch FT, Alexander J. Psychogenic polydipsia: hidden or underdiagnosed? Aust N Z J Psychiatry 2011;45:789-90.

169 Bayir PT, Demirkan B, Duyuler S, et al. Water intoxication resulting in ventricular arrythmias. Turkiye Acil Tip Dergisi 2012;12:188-90.

170 Coler C, Hoffman MD, Towle G, et al. Hyponatremia in an 85-year-old hiker: when depletion plus dilution produces delirium. Wilderness Environ Med 2012;23:153-7.

171 Radojevic N, Bjelogrlic B, Aleksic V, et al. Forensic aspects of water intoxication: four case reports and review of relevant literature. Forensic Sci Int 2012;220:1-5.

172 Su M, Woo H. Severe hyponatremia from water intoxication associated with preparation for a urine flow study. J Med Cases 2012;3:123-5.

173 Adetoki A, Evans R, Cassidy G. Polydipsia with water intoxication in treatment-resistant schizophrenia. Prog Neurol Psychiatry 2013;17:20-3.

174 Cicognani C, Vezzadini C, Zoni R, et al. An overlooked cause of acute symptomatic seizures: psychogenic polydipsia. Am J Med 2013;126:e1-2.

$175 \mathrm{Narcl} \mathrm{H}$. Acute pulmonary edema due to excessive water intake in pyschiatric patient. Iran Red Crescent Med J 2013;15:375-6.

176 Parkinson F, Hopper AN, Eggert S, et al. An interesting case of acute, severe postoperative hyponatraemia following carotid endarterectomy. BMJ Case Rep 2013;2013:bcr2012008299.

177 Chen J-J, Chang H-F, Chen D-L. Recurrent episodic vertigo secondary to hyponatremic encephalopathy from water intoxication. Neurosciences 2014;19:328-30.

178 Cortejoso L, Gómez-Antúnez M, Muiño-Míguez A, et al. Acyclovir and hyponatremia: a case report. Am J Ther 2014;21:e151-3.

179 Kowalski PC, Dowben JS, Keltner NL. Biological perspectives. Perspect Psychiatr Care 2014;50:221-3.

180 Moshiri K, Narasimhan D, Dharmarajan T. Hyponatremia induced by thiazides in setting of primary polydipsia. J Am Geriatr Soc 2014;1:S81

181 Nagasawa S, Yajima D, Torimitsu S, et al. Fatal water intoxication during olanzapine treatment: a case report. Leg Med 2014; 16:89-91

182 Kawashima W, Hatake K, Kudo R. Two autopsy cases of water intoxication. J Forensic 2015;6:2.

183 Madero M, Monares E, Domínguez AM, et al. Acute symptomatic hyponatremia in a flight attendant. Clin Nephrol 2015;84:108-10.

184 Mirvis E, De-Silva D, Mehta A. Hyponatraemia in patients with multiple myeloma. BMJ Case Rep 2015;2015:11.

185 Penders TM, Stanciu CN, Ganpat P, et al. Psychogenic polydipsia, hyponatremia and osmotic myelinolysis. BMJ Case Rep 2015;2015:bcr2014207508.

186 Scotney B, Reid S, Weight B. Body weight, serum sodium levels, and renal function in an Ultra-Distance mountain run. Clin J Sport Med 2015;25:341-6.

187 Yong SA, Reid DA, Tobin AE. Heatwave hyponatraemia: a case series at a single Victorian tertiary centre during January 2014 Intern Med J 2015;45:211-4.

188 Chen Y-W, Chung W, Wu C-K, et al. Effective and cheap behavioral modification therapy to manage complicated polydipsia and seizures in a chronic mental health institute. Acta Neurol Taiwan 2016;25:41-4.

189 Dubin I, Gelber M, Schattner A. Rare times rare: the hyponatremia, rhabdomyolysis, anterior compartment syndrome sequence. JRSM Open 2016;7:2054270416629326.

190 Lai J, Lu Q, Xu Y, et al. Severe water intoxication and secondary depressive syndrome in relation to delusional infestation. Neuropsychiatr Dis Treat 2016;12:517-21. 
191 Leban V, Kozelj G, Brvar M. The syndrome of inappropriate antidiuretic hormone secretion after giant leaf frog (Phyllomedusa bicolor) venom exposure. Toxicon 2016;120:107-9

192 Losonczy LI, Lovallo E, Schnorr CD, et al. Drinking to near death--acute water intoxication leading to neurogenic stunned myocardium. Am J Emerg Med 2016;34:119.e3-119.e4.

193 Suzuki H, Hasegawa I, Mishima S, et al. An autopsy case of fatal water intoxication with postmortem computed tomography findings of diluted intestinal content and hemodilution. Journal of Forensic Radiology and Imaging 2016;7:43-6.

194 Kashiura M, Sugiyama K, Hamabe Y. Association between rapid serum sodium correction and rhabdomyolysis in water intoxication: a retrospective cohort study. J Intensive Care 2017;5:37.

195 Pal R, Das L, Dutta P, et al. Secondary parkinsonism in a patient of psychogenic polydipsia. BMJ Case Rep 2017;35:26.

196 Pupić-Bakrač J, Radović J, Pupić-Bakrač A, et al. Severe hyponatremia and water intoxication - diagnostic challenge in department of emergency medicine. Alcoholism and psychiatry research 2017;53:147-54.

197 Wicke F, Moreitz S, Weidauer S. Osmotic demyelination syndrome due to severe hyponatremia mimicking hypoxic encephalopathy. Fortschr Neurol Psychiatr 2017;85:212-5.

198 Windpessl M, Schwarz C, Wallner M. "Bowel prep hyponatremia" a state of acute water intoxication facilitated by low dietary solute intake: case report and literature review. BMC Nephrol 2017;18:54.

199 Roche D, McDonnell TM, Stassen LF. Severe hyponatremia don't forget to check cortisol! Irish Journal of Medical Science 2018;187:S107-8.

200 Salathe C, Blanc A-L, Tagan D. Siadh and water intoxication related to ecstasy. BMJ Case Rep 2018;5:29.

201 Sato H, Hayashi K, Mikada A, et al. Acute water intoxication in an older woman despite a relatively small amount of water loading. Geriatr Gerontol Int 2018;18:813-4.

202 Vanhaebost J, Palmiere C, Scarpelli MP, et al. Postmortem diagnosis of hyponatremia: case report and literature review. Int $J$ Legal Med 2018;132:173-9.

203 Nolte HW, Nolte K, Hew-Butler T. Ad libitum water consumption prevents exercise-associated hyponatremia and protects against dehydration in soldiers performing a $40-\mathrm{km}$ route-march. Mil Med Res 2019;6:1.

204 Solomon N, Many A, Orbach R, et al. Maternal and neonatal hyponatremia during labor: a case series. J Matern Fetal Neonatal Med 2019;32:2711-5.

205 Dietary Reference Intakes for Water, Potassium, Sodium, Chloride and Sulfate, ed. P.o.D.R.I.f.E.a. Water. Washington, D.C: The National Academic Press, 2005

206 National Health and Medical Research Council of Australia and the Ministry of Health, New Zealand. Nutrient reference values for Australia and New Zealand for water, 2006. Available: https://www. nrv.gov.au/nutrients/water
207 Sui Z, Zheng M, Zhang M, et al. Water and beverage consumption: analysis of the Australian 2011-2012 national nutrition and physical activity survey. Nutrients 2016;8. doi:10.3390/nu8110678. [Epub ahead of print: 26 Oct 2016].

208 Knepper MA, Kwon T-H, Nielsen S. Molecular physiology of water balance. N Engl J Med 2015;372:1349-58.

209 Knepper MA. Molecular physiology of urinary concentrating mechanism: regulation of aquaporin water channels by vasopressin. Am J Physiol 1997;272:F3-12.

210 Mercier-Guidez E, Loas G. Polydipsia and water intoxication in 353 psychiatric inpatients: an epidemiological and psychopathological study. Eur Psychiatry 2000;15:306-11.

211 Speedy DB, Noakes TD, Rogers IR, et al. Hyponatremia in ultradistance triathletes. Med Sci Sports Exerc 1999;31:809-15.

212 O'Toole ML, Douglas PS, Laird RH, et al. Fluid and electrolyte status in athletes receiving medical care at an ultradistance triathlon. Clin $J$ Sport Med 1995;5:116-22.

213 Tiller NB, Roberts JD, Beasley L, et al. International Society of sports nutrition position stand: nutritional considerations for singlestage ultra-marathon training and racing. J Int Soc Sports Nutr 2019;16:50.

214 Johnson EC, Muñoz CX, Jimenez L, et al. Hormonal and thirst modulated maintenance of fluid balance in young women with different levels of habitual fluid consumption. Nutrients 2016;8. doi:10.3390/nu8050302. [Epub ahead of print: 18 May 2016].

215 Rees R, Leach D. The social inhibition of micturition (paruresis): sex similarities and differences. J Am Coll Health Assoc 1975;23:203-5.

216 Spasovski G, Vanholder R, Allolio B, et al. Clinical practice guideline on diagnosis and treatment of hyponatraemia. Nephrol Dial Transplant 2014;29 Suppl 2:i1-39.

217 Renneboog B, Musch W, Vandemergel X, et al. Mild chronic hyponatremia is associated with falls, unsteadiness, and attention deficits. Am J Med 2006;119:71.e1-71.e8.

218 Fujisawa $\mathrm{H}$, Sugimura $\mathrm{Y}$, Takagi $\mathrm{H}$, et al. Chronic hyponatremia causes neurologic and psychologic impairments. J Am Soc Nephrol 2016;27:766-80.

219 King JD, Rosner MH. Osmotic demyelination syndrome. Am J Med Sci 2010;339:561-7.

220 George JC, Zafar W, Bucaloiu ID, et al. Risk factors and outcomes of rapid correction of severe hyponatremia. Clin J Am Soc Nephrol 2018;13:984-92.

221 Aratani S, Hara M, Nagahama M, et al. A low initial serum sodium level is associated with an increased risk of overcorrection in patients with chronic profound hyponatremia: a retrospective cohort analysis. BMC Nephrol 2017;18:316.

222 Hoorn EJ, Spasovski G. Recent developments in the management of acute and chronic hyponatremia. Curr Opin Nephrol Hypertens 2019;28:424-32.

223 Blum A, Friedland GW. Urinary tract abnormalities due to chronic psychogenic polydipsia. Am J Psychiatry 1983;140:915-6. 